\title{
A Goal Programming Approach To Human Resource Planning With A Concentration On Promotion Policy
}

Joseph G. Glynn (glynn@ canisius.edu), Canisius College

\begin{abstract}
Goal programming will be employed to assist human resource managers in identifying a promotion policy that will provide a desired future distribution of managers at various levels in an organization. The goal programming model will be developed and exemplified for a small firm with only two job classifications. Model inputs include the current inventory of managers and a desired future distribution of these managers. The model output will be an identified "optimal" promotion policy that will achieve the desired future assignments of managers.
\end{abstract}

\section{INTRODUCTION}

Among the primary functions of human resource management is the allocation of managers to various job assignments over time. In this work, job assignments will refer to level in the organization or job classification. The job classifications will be designated as M1 for level one managers, M2 for level two managers, M3, M4, and so on, and an "E" designation to account for managers exiting or leaving the organization. A goal programming model will be developed to assist the human resource planning team. The fundamental rationale for and characteristics of the model can be summarized as:

1. The task to be modeled is the identification of a promotion policy that will, given a current supply of managers at the various levels, provide a desired future distribution of these managers across those levels within the firm.

2. The model will accept the current inventory of managers and a desired future distribution of these managers as inputs.

3. The Model will seek to determine an optimal promotion policy that will achieve the desired future assignments of managers while remaining as close as possible to an "ideal" target promotion policy identified by the human resource planning team.

4. Though the emphasis will initially be upon promotion policy, allowances for recruitment of new managers will be accommodated in cases where promotion policy alone is ineffective in meeting future human resource requirements.

\section{EXAMPLE - TWO MANAGERIAL CLASSIFICATIONS}

A small company has only two levels of managers - M1 and M2. There are currently $400 \mathrm{M} 1 \mathrm{~s}$ and 100 M2s with the firm. The recent promotion policy is represented in Table 1 as proportions of managers moving from the job classifications listed down the left side of the table to the positions listed across the top. It is seen that within the M1 job classification, 70 percent of M1s stay M1s in any year, 10 percent get promoted to M2, and 20 percent leave the organization (E). With respect to M2s, 5 percent get demoted to M1, 85 percent stay M2s, and 10 percent leave in any year. In this example, the firm's most recent promotion policy will be referred to as the "target promotion policy." 
Table 1 Recent Promotion Policy

\begin{tabular}{|l|l|l|l|l|}
\hline & & \multicolumn{3}{|c|}{ Position Next Year } \\
\hline & & M1 & M2 & E \\
\hline Current & M1 & 0.70 & 0.10 & 0.20 \\
\hline Position & M2 & 0.05 & 0.85 & 0.10 \\
\hline
\end{tabular}

\section{Traditional Model Representation}

Human resource planning models have taken a variety of forms. Linear optimization models have been presented and employed since the 1970s. Traditional Markov analysis has been successfully used to predict future distributions of current managerial resources. The human resource planning problem may be diagramed via the traditional INPUT $\rightarrow$ PROCESSOR $\rightarrow$ OUTPUT model representation. In the traditional Markov models, the input is the current managerial distribution and the processor is the promotion policy represented as a transition probability matrix similar to Table 1. The output to be determined by the model is the distribution of managers one year into the future.

INPUT

Given

\section{PROCESSOR}

Given
Current Distribution of Mgrs.: $\rightarrow \quad$ Promotion $\quad \rightarrow \quad$ Distribution of Mgrs. One year Hence: M1, M2, etc.

OUTPUT

**Result to be Determined**

This traditional form of Markov analysis is used below to depict how the current 400 M1 and 100 M2 managers will move through the organization via the current promotion policy to yield $285 \mathrm{M} 1 \mathrm{~s}$ and $125 \mathrm{M} 2 \mathrm{~s}$ one year from now.

\begin{tabular}{|c|c|c|c|c|c|c|c|c|c|c|}
\hline \multicolumn{3}{|c|}{ Given } & \multicolumn{4}{|c|}{ Given } & & \multicolumn{3}{|c|}{ Output } \\
\hline M1 & M2 & $\mathrm{E}$ & & M1 & M2 & $\mathrm{E}$ & \multirow{4}{*}{$=$} & M1 & M2 & $\mathrm{E}$ \\
\hline \multirow[t]{3}{*}{400} & \multirow[t]{3}{*}{100} & \multirow[t]{3}{*}{ 0] } & M1 & .70 & .10 & .20 & & {$[285$} & \multirow[t]{3}{*}{125} & 90] \\
\hline & & & M2 & .05 & .85 & .10 & & & & \\
\hline & & & $\mathrm{E}$ & 0 & 0 & 1 & & & & \\
\hline
\end{tabular}

Table 2 shows the details concerning the counts of managers who would get promoted, those who would get demoted, those who would stay in the same job classification, and those who would leave the organization in year one if the current (target) promotion policy were used. Note that this promotion policy would supply: $285 \mathrm{M} 1 \mathrm{~s}$ by keeping $280 \mathrm{M} 1 \mathrm{~s}$ as M1s and demoting $5 \mathrm{M} 2 \mathrm{~s}$ to M1; $125 \mathrm{M} 2 \mathrm{~s}$ by keeping $85 \mathrm{M} 2 \mathrm{~s}$ as M2s and promoting 40 M1s to M2; and allow for 90 managers to leave the organization with 80 leaving from M1 and 10 leaving from M2.

Table 2 First Year Managerial Transitions via Current Promotion Policy

\begin{tabular}{|l|c|c|c|c|c|}
\hline & & \multicolumn{4}{|c|}{ Position Next Year } \\
\hline & & M1 & M2 & E & \\
\hline Current & M1 & 280 & 40 & 80 & 400 \\
\hline Position & M2 & 5 & 85 & 10 & 100 \\
\hline & & & & & \\
\hline & Totals & 285 & 125 & 90 & 500 \\
\hline
\end{tabular}




\section{States of the System}

All of the managers move through the organization from one job level to another, stay at the same job level, or leave the organization. Their position or job description at any point in time will be referred to as the "state of the system." The states are simply the job level descriptors M1, M2, etc. and an exit state E that accommodates the occurrence of managers leaving the firm. The exit state represents the aggregation of managers who leave via voluntary or involuntary terminations, or retirement. Movements through the system (transitions) will occur in one year time frames, and thus represent annual promotions, demotions, staying at the same managerial level, or leaving the organization.

\section{Variables}

$\mathrm{Mi}$ - Number of managers at managerial level i [for example, M1, M2, etc.].

$\mathrm{MiMj}$ - Number of managers currently at level $\mathrm{i}$ who will be at level $\mathrm{j}$ one year from now. M1M1 = number of current M1 managers who stay in M1.

M1M2 = number of current M1 managers who get promoted to M2.

M2M1 = number of current M2 managers who get demoted to M1.

$\mathrm{M} 2 \mathrm{M} 2$ = number of current M2 managers who stay in M2.

MiE - Number of managers who leave the company from job classification Mi.

$\mathrm{M} 1 \mathrm{E}=$ number of current M1 managers who leave.

$\mathrm{M} 2 \mathrm{E}=$ number of current $\mathrm{M} 2$ managers who leave.

$\mathrm{RMi}-$ Number of managers to be recruited for job classification Mi.

RM1 = number of managers recruited to meet future requirement in M1.

$\mathrm{RM} 2$ = number of managers recruited to meet future requirement in M2.

\section{Goal Programming Model Representation}

With respect to the general INPUT $\rightarrow$ PROCESSOR $\rightarrow$ OUTPUT model representation, the model presented in this work will accept the INPUT and OUTPUT as givens, and the PROCESSOR becomes the result to be determined. In other words, for a given supply of currents managers at various levels (INPUT) and a given desired distribution of managers one year hence (OUTPUT), the goal programming model will identify a promotion policy (PROCESSOR) that will yield the desired future managerial inventory.

\begin{tabular}{|c|c|c|c|c|}
\hline $\begin{array}{l}\text { INPUT } \\
\text { Given }\end{array}$ & & $\begin{array}{l}\text { PROCESSC } \\
\text { it to be Dete }\end{array}$ & & $\begin{array}{l}\text { OUTPUT } \\
\text { Given }\end{array}$ \\
\hline $\begin{array}{l}\text { Current Supply of Managers: } \\
\text { M1, M2, M3, etc. }\end{array}$ & $\rightarrow$ & $\begin{array}{l}\text { Promotion } \\
\text { Policy }\end{array}$ & $\rightarrow$ & $\begin{array}{l}\text { Distribution of Managers One } \\
\text { Year Hence: M1, M2, M3, etc. }\end{array}$ \\
\hline
\end{tabular}

For example, assume that the current distribution of managers is still $400 \mathrm{M} 1 \mathrm{~s}$ and $100 \mathrm{M} 2 \mathrm{~s}$. The human resource planners have forecasted needs for $300 \mathrm{M} 1 \mathrm{~s}$ and $150 \mathrm{M} 2 \mathrm{~s}$ one year from now. The problem becomes one of determining an appropriate promotion policy that would yield the desired $300 \mathrm{M} 1 \mathrm{~s}$ and $150 \mathrm{M} 2 \mathrm{~s}$ one year hence, while remaining as similar as possible to the current or target promotion policy.

\begin{tabular}{|c|c|c|c|c|c|c|c|c|c|c|}
\hline \multirow{3}{*}{$\begin{array}{c}\text { M1 } \\
{[400}\end{array}$} & \multirow{2}{*}{$\begin{array}{r}\text { Given } \\
\text { M2 }\end{array}$} & \multirow[b]{2}{*}{$\mathrm{E}$} & & \multicolumn{3}{|c|}{ Output } & \multicolumn{4}{|c|}{ Given } \\
\hline & & & \multirow{4}{*}{$\begin{array}{c}\text { M1 } \\
\text { M2 } \\
\text { E }\end{array}$} & M1 & M2 & E & \multirow{4}{*}{$=$} & \multirow{4}{*}{$\begin{array}{c}\text { M1 } \\
{[300}\end{array}$} & M2 & $\mathrm{E}$ \\
\hline & \multirow{3}{*}{100} & \multirow[t]{3}{*}{ 0] } & & $?$ & $?$ & $?$ & & & 150 & 50] \\
\hline & & & & $?$ & $?$ & $?$ & & & & \\
\hline & & & & 0 & 0 & 1 & & & & \\
\hline
\end{tabular}




\section{Target Promotion Policy}

Recall that it is desirable to identify a new promotion policy that would conform as closely as possible to an identified ideal promotion policy - thus the name target promotion policy. The model will have the goal of identifying a new promotion policy that mirrors this ideal promotion policy. In this work, that ideal policy is the current promotion policy. So the current promotion policy and the target promotion policy are one in the same. The term target is useful as the goal constraints in the goal programming model are directed towards keeping the identified promotion policy close to the "target" or current promotion policy.

Table 2 shows how the 400 M1 managers and the 100 M2 managers would move through the organization in the first year if the current (target) promotion policy were used. The new promotion policy, which is to be identified by the goal programming model, should come as close as possible to supplying $280 \mathrm{M} 1 \mathrm{M} 1 \mathrm{~s}, 40 \mathrm{M} 1 \mathrm{M} 2 \mathrm{~s}$, 80 M1Es, 5 M2M1s, 85 M2M2s, and 10 M2Es (see Table 2). These "targets" will define the goal constraints of the model. Once again, as Table 2 shows, with this current or target promotion policy there would be $285 \mathrm{M} 1 \mathrm{~s}$ and 125 M2s next year, and 90 managers would leave the firm.

\section{Forecasted Requirements}

Assume that forecasts (exogenous to this model) of M1 and M2 level managerial requirements one year from now are made yielding an anticipated need for $300 \mathrm{M} 1$ and $150 \mathrm{M} 2$ level managers. The forecasted requirements and promotion policy goals from Table 2 are shown in Table 3. The distinction between goals and requirements is integral to an understanding of the goal programming model to be developed. The forecasts of needed M1s and M2s are the requirements (marked with an * in Table 3). The model will meet these requirements for $300 \mathrm{M} 1 \mathrm{~s}$ and $150 \mathrm{M} 2 \mathrm{~s}$ via promotion policy as long as: (a) the sum of total managers required for next year is less than or equal to the sum of total managers currently with the organization, and (b) promotion policy allows for movements of managers between job classifications.

Table 3 Next Year Requirements and Goals

\begin{tabular}{|c|c|c|c|}
\hline $\begin{array}{l}\text { Job } \\
\text { Level }\end{array}$ & $\begin{array}{l}\text { Current } \\
\text { Staffing } \\
\end{array}$ & $\begin{array}{c}1^{\text {st }} \text { Year } \\
\text { Transition }\end{array}$ & $\begin{array}{l}\text { Next Year } \\
\text { Goal/Req* }\end{array}$ \\
\hline \multirow[t]{3}{*}{ M1 } & 400 & & $300 *$ \\
\hline & & M1M1 & 280 \\
\hline & & M2M1 & 5 \\
\hline \multirow[t]{3}{*}{ M2 } & 100 & & $150^{*}$ \\
\hline & & M1M2 & 40 \\
\hline & & M2M2 & 85 \\
\hline \multirow[t]{3}{*}{$\mathrm{E}$} & - & & 50 \\
\hline & & M1E & 80 \\
\hline & & M2E & 10 \\
\hline
\end{tabular}

\section{Goals}

The goals come from the target promotion policy and are represented by the numbers of managers who would be promoted, demoted, or remain where they are if the current promotion policy were used. Refer to the M1 job classification in Table 3. The model will supply the forecasted requirement for $300 \mathrm{M} 1 \mathrm{~s}$. The only sources of M1s are current M1s and current M2s. Note from Table 2 that the target promotion policy would supply only 285 M1s: 280 M1M1s + 5 M2M1s. Thus, two of the goals of the model are to identify a promotion policy that would provide as close as possible to $280 \mathrm{M} 1 \mathrm{M} 1 \mathrm{~s}$ and $5 \mathrm{M} 2 \mathrm{M} 1 \mathrm{~s}$.

In summary, the model must supply $300 \mathrm{M} 1 \mathrm{~s}$, so M1M1 + M2M1 must be 300. The model will supply the $300 \mathrm{M} 1 \mathrm{~s}$ by identifying a promotion policy as "close as possible" to the current promotion policy, or M1M1 will be kept close to 280 and M2M1 will be kept close to 5 . 


\section{GOAL PROGRAMMING MODEL}

\section{Variables (replicated for reader convenience)}

$\mathrm{Mi}$ - $\quad$ Number of managers at managerial level i [for example, M1, M2, etc.].

$\mathrm{MiMj}$ - $\quad$ Number of managers currently at level $\mathrm{i}$ who will be at level $\mathrm{j}$ one year from now [for example, $1 \mathrm{M} 2$ = Number of current M1 managers who get promoted to M2].

MiE - $\quad$ Number of managers who leave the company from job classification Mi. [for example, M1E = number of current M1 managers who leave].

RMi - $\quad$ Number of managers to be recruited for job classification Mi. [for example, RM2 = number of managers recruited to meet future requirement in M2].

\section{Supply Equality Constraints [these must be met exactly]}

1. $\quad$ M1 Supply: M1M1 + M1M2 + M1E $=400$

2. $\quad$ M2 Supply: M2M1 + M2M2 + M2E $=100$

Constraints 1 and 2 show where the current 400 M1s and 100 M2s may move. For example, in constraint 1, the 400 current M1s are allowed to stay in M1, be promoted to M2, or leave the company.

\section{Requirement Equality Constraints [these must be met exactly]}

3. M1 Requirement: M1M1 + M2M1 + RM1 $=300$

4. M2 Requirement: M1M2 + M2M2 + RM2 $=150$

Constraints 3 and 4 depict how the required forecasts can be met via a combination of promotion and recruitment policies. Constraint 4 shows the requirement of $150 \mathrm{M} 2 \mathrm{~s}$ can be met by promotions from M1, M2 managers staying where they are, and, if necessary, recruiting managers from outside the firm.

\section{Goal Constraints and Deviation Variables [attempts to mirror target promotion policy]}

5. $\quad$ M1M1 Goal: M1M1 $-\mathrm{d} 1++\mathrm{d} 1-=280$

6. M1M2 Goal: M1M2 $-\mathrm{d} 2++\mathrm{d} 2-=40$

7. M1E Goal: $\mathrm{M} 1 \mathrm{E}-\mathrm{d} 3++\mathrm{d} 3-=80$

8. $\quad$ M2M1 Goal: M2M1 $-\mathrm{d} 4++\mathrm{d} 4-=5$

9. $\quad$ M2M2 Goal: M2M2 $-\mathrm{d} 5++\mathrm{d} 5-=85$

10. M2E Goal: $\quad \mathrm{M} 2 \mathrm{E}-\mathrm{d} 6++\mathrm{d} 6-=10$

These goals and the associated deviation variables lie at the heart of goal programming. Each goal has an allowance for variation from the goal. That allowance takes the form of the deviation variables $\mathrm{d}+$ and $\mathrm{d}$ - that are a part of each goal constraint. Using the M1M1 goal as an example, the goal is to have the model supply 280 of the M1 managers by keeping $280 \mathrm{M} 1 \mathrm{~s}$ right where they are - this is what the target promotion policy would have done. The deviation variables allow for surpluses above the 280 goal (d1+) or for shortages below the 280 goal (d1-). Table 4 below shows values of the deviation variables for three possible values of M1M1 in constraint 5 above (the first goal constraint).

One way to think of the deviation variables is that they allow for noncompliance in the equality constraints. That is, the deviation variables allow for amounts above or below the targets specified in the right-hand-side constants of the goal constraints. An important attribute of this function is that it guarantees feasible solutions. 
Table 4 Examples of Values of Deviation Variables For M1M1 Goal

\begin{tabular}{|l|c|c|c|}
\hline $\begin{array}{l}\text { M1M1 } \\
\text { Goal }\end{array}$ & $\begin{array}{c}\text { Possible M1M1 } \\
\text { Values }\end{array}$ & $\mathrm{d}+$ & $\mathrm{d}-$ \\
\hline & & & \\
\hline 280 & 255 & 0 & 25 \\
\hline 280 & 300 & 20 & 0 \\
\hline 280 & 280 & 0 & 0 \\
\hline
\end{tabular}

\section{Priorities and Weights Associated With the Deviation Variables}

Priorities and weights are assigned to the deviation variables to reflect the relative importance of meeting the goal. Lower priority numbers reflect more importance than higher priority numbers. Goal programming will attempt to meet all priority 1 goals before considering priority 2 goals. When priority 1 goals have been satisfied as much as is possible, then attempts will be made to satisfy priority 2 goals. Priority 2 goals will never be satisfied at the expense of priority 1 goals. Within priorities, the deviation variables may also be weighted. Higher weights reflect more importance, and within any priority level, the model will attempt to meet the goals with the more highly weighted deviation variables first.

\section{GOAL PROGRAMMING SOLUTION}

Table 5 displays the goal programming inputs and the output of the first run. The first four columns of Table 5 are the same as Table 3. For M1, the requirement of 300 managers must be supplied. The goals, determined from the current or target promotion policy, are to provide $280 \mathrm{M} 1 \mathrm{~s}$ from M1 and $5 \mathrm{M} 1 \mathrm{~s}$ by demotions from M2. All goals have priorities and weights of 1. The solution appears under "Next Year Staffing." The reader is encouraged to verify that the newly identified promotion policy will provide $300 \mathrm{M} 1 \mathrm{~s}$ and $150 \mathrm{M} 2 \mathrm{~s}$ as required, and that 50 managers will leave the firm.

In this small problem the restrictiveness of the constraints is clear. It is easily seen why the goals are unattainable. Recall that forecasted requirements are in equality constraint form, and therefore must be met exactly. The policy goals are in goal programming constraint form and thus allow for deviations from the stated goals. For example, the M1 forecasted requirement for next year is 300, and the policy goals for supplying M1s are M1M1 = 280 and M2M1 $=5$. There has to be an aggregate overachievement (surplus) of 15 on the M1 supply goals. Indeed, the Next Year Staffing column that represents the newly identified promotion policy shows that 295 M1M1s and 5 M2M1s will be supplied by the newly identified promotion policy.

Table 5 All Goal Priorities = 1, Weights = 1, No Recruiting

\begin{tabular}{|c|c|c|c|c|c|c|}
\hline $\begin{array}{c}\text { Job } \\
\text { Level }\end{array}$ & $\begin{array}{c}\text { Current } \\
\text { Staffing }\end{array}$ & $\begin{array}{c}1^{\text {st }} \text { Year } \\
\text { Transition }\end{array}$ & $\begin{array}{c}\text { Next Year } \\
\text { Goal/Req* }\end{array}$ & $\begin{array}{c}\text { Priority/ } \\
\text { Weight }\end{array}$ & $\begin{array}{c}\text { Next Year } \\
\text { Staffing }\end{array}$ & $\begin{array}{c}\text { Short (-) } \\
\text { Surplus (+) }\end{array}$ \\
\hline M1 & 400 & & $300^{*}$ & & & +15 \\
\hline & & M1M1 & 280 & $1 / 1$ & 295 & \\
\hline & & M2M1 & 5 & $1 / 1$ & 5 & \\
\hline M2 & 100 & & $150^{*}$ & & & \\
\hline & & M1M2 & 40 & $1 / 1$ & 65 & +25 \\
\hline & & M2M2 & 85 & $1 / 1$ & 85 & -40 \\
\hline E & - & & $50^{*}$ & & & \\
\hline & & M1E & 80 & $1 / 1$ & 10 & \\
\hline
\end{tabular}

In like manner, with a forecasted requirement of $150 \mathrm{M} 2 \mathrm{~s}$, the policy goals of $40 \mathrm{M} 1 \mathrm{M} 2 \mathrm{~s}$ and $85 \mathrm{M} 2 \mathrm{M} 2 \mathrm{~s}$ guarantee an overachievement of 25 on the M2 supply goals. The Next Year Staffing column shows that the 150 M2s will be supplied by promoting $65 \mathrm{M} 1 \mathrm{~s}$ (65 M1M2s) and by keeping 85 M2s right where they are (85 M2M2s). 
The solution depicted in Table 5 is represented in Table 6 in a form that will clearly show how managers are moving through the organization.

Table 6 First Year Managerial Transitions

\begin{tabular}{|l|c|c|c|c|c|}
\hline & & \multicolumn{3}{|c|}{ Position Next Year } & \\
\hline & & M1 & M2 & E & \\
\hline Current & M1 & 295 & 65 & 40 & 400 \\
\hline Position & M2 & 5 & 85 & 10 & 100 \\
\hline & & 300 & 150 & 50 & 500 \\
\hline
\end{tabular}

Table 6 reveals that there were originally $400 \mathrm{M} 1 \mathrm{~s}$ and $100 \mathrm{M} 2 \mathrm{~s}$. Of the $400 \mathrm{M} 1 \mathrm{~s}, 295$ remain M1s, 65 get promoted to M2, and 40 leave the firm in the first year. Five of the $100 \mathrm{M} 2 \mathrm{~s}$ get demoted to M1, 85 stay on as M2s, and 10 leave the firm. The forecasted requirements for $300 \mathrm{M} 1 \mathrm{~s}$ and $150 \mathrm{M} 2 \mathrm{~s}$ will be met. This is a feasible solution in a goal programming sense - goal programming models guarantee feasible solutions. The human resource managers must assess the feasibility from a real world perspective. If the solution is not satisfactory, three options exist:

1. weights and/or priorities may be changed on the policy goals,

2. managers may be recruited from without the company, and

3. forecasted requirements may be relaxed.

\section{Adjusting Weights on Policy Goals}

Viewing the solution depicted in Table 5, the human resource planners have decided the surplus of +25 M1M2s is troubling. The surplus is +25 since the model suggests the promotion of 65 managers from M1 to M2, while the target was for 40 managers. Weights on the deviation variables for the M1M2 goal are raised from 1 to 2 , and results are shown above in Table 7 where it is seen that progress was made with respect to M1M2 managers. The previous solution in Table 5 had M1M2 $=65$ (surplus of +25 above the target of 40), while the solution of Table 7 shows that 55 managers should be promoted from M1 to M2 (surplus of +15 ).

Table 7 Increase Weight on M1M2 Goal to 2

\begin{tabular}{|c|c|c|c|c|c|c|}
\hline $\begin{array}{c}\text { Job } \\
\text { Level }\end{array}$ & $\begin{array}{l}\text { Current } \\
\text { Staffing }\end{array}$ & $\begin{array}{c}1^{\text {st }} \text { Year } \\
\text { Transition }\end{array}$ & $\begin{array}{l}\text { Next Year } \\
\text { Goal/Req* }\end{array}$ & $\begin{array}{l}\text { Priority/ } \\
\text { Weight }\end{array}$ & $\begin{array}{c}\text { Next Year } \\
\text { Staffing }\end{array}$ & $\begin{array}{c}\text { Short (-) } \\
\text { Surplus (+) }\end{array}$ \\
\hline \multirow[t]{3}{*}{ M1 } & 400 & & $300 *$ & & & \\
\hline & & M1M1 & 280 & $1 / 1$ & 295 & +15 \\
\hline & & M2M1 & 5 & $1 / 1$ & 5 & \\
\hline \multirow[t]{3}{*}{ M2 } & 100 & & $150^{*}$ & & & \\
\hline & & M1M2 & 40 & $1 / 2$ & 55 & +15 \\
\hline & & M2M2 & 85 & $1 / 1$ & 95 & +10 \\
\hline \multirow[t]{3}{*}{ E } & - & & $50 *$ & & & \\
\hline & & M1E & 80 & $1 / 1$ & 50 & -30 \\
\hline & & M2E & 10 & $1 / 1$ & 0 & -10 \\
\hline
\end{tabular}

\section{Changing Priorities of Policy Goals}

The human resource planners are still not satisfied with a promotion policy that would promote 55 managers from M1 to M2. In another attempt to get M1M2 closer to the target goal of 40, the priority of the M1M2 goal is kept at 1, while all other goal priorities are set to 2. Recall that lower priority numbers represent higher priorities. Thus, goal programming will attempt to meet the priority $1 \mathrm{M} 1 \mathrm{M} 2$ goal before consideration of any of the other goals in the model (all other goals are now priority 2 goals). Table 8 displays the results. 
Table 8 Keep Priority on M1M2 Goal = 1, Set All Others = 2

\begin{tabular}{|c|c|c|c|c|c|c|}
\hline $\begin{array}{c}\text { Job } \\
\text { Level }\end{array}$ & $\begin{array}{l}\text { Current } \\
\text { Staffing }\end{array}$ & $\begin{array}{c}1^{\text {st }} \text { Year } \\
\text { Transition }\end{array}$ & $\begin{array}{l}\text { Next Year } \\
\text { Goal/Req* }\end{array}$ & $\begin{array}{c}\text { Priority/ } \\
\text { Weight }\end{array}$ & $\begin{array}{c}\text { Next Year } \\
\text { Staffing }\end{array}$ & $\begin{array}{c}\text { Short (-) } \\
\text { Surplus (+) }\end{array}$ \\
\hline \multirow[t]{3}{*}{ M1 } & 400 & & $300 *$ & & & \\
\hline & & M1M1 & 280 & $2 / 1$ & 300 & +20 \\
\hline & & M2M1 & 5 & $2 / 1$ & 0 & -5 \\
\hline \multirow[t]{3}{*}{ M2 } & 100 & & $150 *$ & & & \\
\hline & & M1M2 & 40 & $1 / 1$ & 50 & +10 \\
\hline & & M2M2 & 85 & $2 / 1$ & 100 & +15 \\
\hline \multirow[t]{3}{*}{$\mathrm{E}$} & - & & $50 *$ & & & \\
\hline & & M1E & 80 & $2 / 1$ & 50 & -30 \\
\hline & & M2E & 10 & $2 / 1$ & 0 & -10 \\
\hline
\end{tabular}

It is not possible to proceed further via promotion policy to reduce the surplus of +10 on M1M2 managers. In order to meet the required forecast for $150 \mathrm{M} 2 \mathrm{~s}$, at least 50 managers have to be promoted from M1 to M2. This is so because the only other source of M2s is current M2s, and there are only 100 of those managers. Note that the solution in Table 8 does not allow for any M2s to leave the company in the coming year. This is not a feasible solution in a practical real world sense. What have we learned? It is clear that forecasted requirements cannot be met with any realistic promotion policy. The only options open to the human resource planners are:

- $\quad$ use recruitment policy to bring in new M1s and/or M2s,

- $\quad$ back off the forecasted requirements for either M1 (300) or M2 (150).

\section{Modeling of Recruitment Policy}

Recall that RM1 and RM2 represent the numbers of managers recruited to M1 and M2 respectively from outside the organization. RM1 and RM2 appear in the Requirement Equality Constraints 3 and 4 as presented earlier. RM1 and RM2 must also be represented as goal constraints. The complete goal programming model is listed below for the reader's convenience.

\section{Supply Equality Constraints [these must be met exactly]}

1. M1 Supply: M1M1 + M1M2 + M1E $=400$

2. M2 Supply: M2M1 + M2M2 + M2E = 100

Requirement Equality Constraints [these must be met exactly]

3. M1 Requirement: M1M1 + M2M1 + RM1 = 300

4. M2 Requirement: M1M2 + M2M2 + RM2 $=150$

Goal Constraints [attempts to mirror target promotion policy]

5. M1M1 Goal: M1M1 $-\mathrm{d} 1++\mathrm{d} 1-=280$

6. M1M2 Goal: M1M2 $-\mathrm{d} 2++\mathrm{d} 2-=40$

7. M1E Goal: $\mathrm{M} 1 \mathrm{E}-\mathrm{d} 3++\mathrm{d} 3-=80$

8. M2M1 Goal: M2M1 $-\mathrm{d} 4++\mathrm{d} 4-=5$

9. M2M2 Goal: M2M2 - d5 + + d5- = 85

10. M2E Goal: $\mathrm{M} 2 \mathrm{E}-\mathrm{d} 6++\mathrm{d} 6-=10$

11. RM1 Goal: $\mathrm{RM} 1-\mathrm{d} 7++\mathrm{d} 7-=0 *$

12. RM2 Goal: $\mathrm{RM} 2-\mathrm{d} 8++\mathrm{d} 8-=0 *$

* The goals for the recruitment variables RM1 and RM2 were initially set $=0$ and the coefficients on the deviation variables were also set $=0$. Thus, the original recruiting constraints were converted to traditional linear 
programming constraints: $\mathrm{RM} 1=0$, and $\mathrm{RM} 2=0$. In that form, no recruiting was allowed. Initial attempts to achieve a real world feasible human resource plan focused solely upon promotion policy. Should the planners decide that promotion policy alone cannot provide the desired future distribution of managers, then recruiting may be employed to ease the demands made upon the promotion policy.

Goal constraints 5 - 10 are unaltered with the introduction of recruiting into the goal programming model. These constraints deal exclusively with promotion policy and the goals of keeping the newly identified policy as close as possible to the target or current promotion policy. Goal constraints 11 and 12 allow for recruiting of new managers. The human resource planners would determine a maximum number of potential recruits for each job classification. That data would then be entered into the goal programming model by changing the right-hand-side 0s to this allowable number of recruits, and restoring coefficients on the deviation variables to 1 .

The next model run shown in Table 9 allows for the recruiting of at most 10 managers into each of M1 and M2. The goal priorities for the recruiting variables are set $=1$. This is done in recognition of the fact that the human resource planners consider it to be of primary importance not to exceed 10 recruits in either M1 or M2.

All other goal priorities are set to 2 (goal constraints 5-10 above). Earlier model runs represented in Tables 5,7 , and 8 indicated the need to devote some attention to control of M1M2 and M2E. Accordingly, the weights on their deviation variables were set $=2$ while the other deviation variables had weights of 1 .

Table 9 Promotion and Recruitment Policies

\begin{tabular}{|c|c|c|c|c|c|c|}
\hline $\begin{array}{c}\text { Job } \\
\text { Class }\end{array}$ & $\begin{array}{l}\text { Current } \\
\text { Staffing }\end{array}$ & $\begin{array}{l}1^{\text {st }} \text { Year } \\
\text { Transition }\end{array}$ & $\begin{array}{l}\text { Next Year } \\
\text { Goal/Req* }\end{array}$ & $\begin{array}{c}\text { Priority/ } \\
\text { Weight }\end{array}$ & $\begin{array}{l}\text { Next Year } \\
\text { Staffing }\end{array}$ & $\begin{array}{c}\text { Short (-) } \\
\text { Surplus (+) }\end{array}$ \\
\hline \multirow[t]{3}{*}{ M1 } & 400 & & $300 *$ & & & \\
\hline & & M1M1 & 280 & $2 / 1$ & 285 & +5 \\
\hline & & M2M1 & 5 & $2 / 1$ & 5 & \\
\hline \multirow[t]{3}{*}{ M2 } & 100 & & $150^{*}$ & & & \\
\hline & & M1M2 & 40 & $2 / 2$ & 55 & +15 \\
\hline & & M2M2 & 85 & $2 / 1$ & 85 & \\
\hline \multirow[t]{6}{*}{$\mathrm{E}$} & - & & $50 *$ & & & \\
\hline & & M1E & 80 & $2 / 1$ & 60 & -20 \\
\hline & & M2E & 10 & $2 / 2$ & 10 & \\
\hline & & $\begin{array}{c}\text { Next Year } \\
\text { Recruits }\end{array}$ & & & & \\
\hline & & RM1 & 10 & $1 / 1$ & 10 & \\
\hline & & $\mathrm{RM} 2$ & 10 & $1 / 1$ & 10 & \\
\hline
\end{tabular}

\section{The Human Resource Plan}

The human resource plan represented in Table 9 must be evaluated for usability in a real world sense. That is, can the plan be implemented? Is it feasible, for example, to promote 55 managers from M1 to M2 as the model output suggests? Can the number of M1s who leave the organization be limited to 60? Assuming that the human resource planning team is satisfied with the results of the model represented in Table 9, the plan to be implemented may be presented in a more readable format as shown in Table 10. 
Table 10 One Year Human Resource Plan

\begin{tabular}{|l|c|c|c|}
\hline & \multicolumn{3}{|c|}{ Next Year's Managerial Distribution } \\
\hline $\begin{array}{l}\text { Current Numbers of Managers } \\
\downarrow\end{array}$ & M1 & M2 & E (Leave) \\
\hline M1 (400) & 285 & 55 & 60 \\
\hline M2 (100) & 5 & 85 & 10 \\
\hline & & & \\
\hline Total via Promotion Policy & 290 & 140 & 70 \\
\hline & & & \\
\hline New Recruits & 10 & 10 & - \\
\hline & & & 70 \\
\hline Totals & 300 & 150 & \\
\hline
\end{tabular}

\section{CONCLUSIONS}

The fundamental charge of the goal programming model was the identification of a useable promotion policy that would meet forecasted managerial requirements while mirroring, as closely as possible, the target promotion policy. In the example presented, it was assumed that the target promotion policy and the promotion policy currently in use by the organization were one in the same. This is a possible scenario as it may be beneficial to identify a promotion policy that results in promotions (demotions) in line with employee expectations, and thus not "rock the boat" by implementing some radically different new promotion policy. Nonetheless, it should be well noted that the target promotion policy could be any policy the human resource planners wish! That is, any "ideal" promotion policy could be defined and serve as the target promotion policy, or that policy that the goal programming model would seek to emulate.

It is also noteworthy that there are really two levels of feasibility within the goal programming model. The first may be thought of as the technical feasibility or mathematical feasibility of any identified goal programming solution. As previously noted, the proper utilization of the goal constraints (with their associated deviation variables) will ensure a mathematically feasible solution. The second level of feasibility is the "real world" feasibility as assessed by the human resource planners. For example, given the organizational supply of managerial talent, limitations of the recruiting budget, and availability of recruits, the human resource planners always and appropriately have the final word concerning whether or not any plan identified by the goal programming model will actually be implemented.

\section{Acknowledgement}

I thank my very good friend and esteemed colleague Dr. Gordon W. Meyer for his willingness to read this manuscript and provide suggestions for its improvement.

\section{References}

1. Gass, Saul I., "Military Manpower Planning Models," Computers Ops Res, Vol. 18, No. 1, pp. 65-73, 1991.

2. Glynn, Joseph G., "A Goal Programming Application To Human Resource Planning," Proceedings of the International Applied Business Research Conference, San Juan, Puerto Rico, March, 2004.

3. Glynn, Joseph G., "A Managerial Human Resource Planning Model for the Determination and Evaluation of Promotion and Recruitment Policy Mixes," Proceedings of the Decision Sciences Institute National Conference, New Orleans, November, 1979.

4. Hemaida, Ramadan S. and Hupfer, Mary A., "A Multiobjective Model For Managing Faculty Resources," Journal of Applied Business Research, Vol. 11, No. 1, pp. 24-30, Winter, 1994/1995. 